\title{
PORT, a CESM tool for the diagnosis of radiative forcing
}

\author{
A. J. Conley ${ }^{1}$, J.-F. Lamarque ${ }^{1}$, F. Vitt ${ }^{1}$, W. D. Collins ${ }^{2,3}$, and J. Kiehl ${ }^{1}$ \\ ${ }^{1}$ National Center for Atmospheric Research, 1850 Table Mesa Dr., Boulder, CO 80305, USA \\ ${ }^{2}$ Department of Earth and Planetary Science, University of California, Berkeley, CA 94720, USA \\ ${ }^{3}$ Earth Sciences Division, Lawrence Berkeley National Laboratory, Berkeley, CA 94720, USA \\ Correspondence to: A. J. Conley (aconley@ucar.edu)
}

Received: 31 July 2012 - Published in Geosci. Model Dev. Discuss.: 10 September 2012

Revised: 20 February 2013 - Accepted: 13 March 2013 - Published: 10 April 2013

\begin{abstract}
The Parallel Offline Radiative Transfer (PORT) model is a stand-alone tool, driven by model-generated datasets, that can be used for any radiation calculation that the underlying radiative transfer schemes can perform, such as diagnosing radiative forcing. In its present distribution, PORT isolates the radiation code from the Community Atmosphere Model (CAM4) in the Community Earth System Model (CESM1). The current configuration focuses on CAM4 radiation with the constituents as represented in present-day conditions in CESM1, along with their optical properties. PORT includes an implementation of stratospheric temperature adjustment under the assumption of fixed dynamical heating, which is necessary to compute radiative forcing in addition to the more straightforward instantaneous radiative forcing. PORT can be extended to use radiative constituent distributions from other models or model simulations. Ultimately, PORT can be used with various radiative transfer models. As illustrations of the use of PORT, we perform the computation of radiative forcing from doubling of carbon dioxide, from the change of tropospheric ozone concentration from the year 1850 to 2000, and from present-day aerosols. The radiative forcing from tropospheric ozone (with respect to 1850) generated by a collection of model simulations under the Atmospheric Chemistry and Climate Model Intercomparison Project is found to be 0.34 (with an intermodel standard deviation of 0.07 ) $\mathrm{W} \mathrm{m}^{-2}$. Present-day aerosol direct forcing (relative to no aerosols) is found to be $-1.3 \mathrm{~W} \mathrm{~m}^{-2}$.
\end{abstract}

\section{Introduction}

In the IPCC Third Assessment Report, Ramaswamy et al. (2001) defined radiative forcing (RF): "The radiative forcing of the surface-troposphere system due to the perturbation in or the introduction of an agent (say, a change in greenhouse gas concentrations) is the change in net (down minus up) irradiance (solar plus long-wave; in $\mathrm{W} \mathrm{m}^{-2}$ ) at the tropopause after allowing for stratospheric temperatures to readjust to radiative equilibrium, but with surface and tropospheric temperatures and state held fixed at the unperturbed values". This definition of radiative forcing includes the stratospheric temperature adjustment under the assumption of fixed dynamical heating (FDH) as discussed in Kiehl and Boville (1988) and Fels et al. (1980). Radiative forcing is distinguished from instantaneous radiative forcing, in which the stratospheric temperatures are not allowed to readjust to radiative equilibrium.

The Community Earth System Model (CESM1) with the Community Atmosphere Model version 4 (CAM4, Gent et al., 2011) uses a radiation parameterization developed by Briegleb (1992), Collins (1998), and Collins et al. (2002). The CAM4 radiation parameterization computes the scattering and absorption of shortwave (solar) radiation by the atmosphere and surface, as well as the absorption and emission of longwave radiation by the atmosphere and surface. This parameterization applies to atmospheres from the surface to about $1 \mathrm{mb}$ (this upper limit is due to the lack of non-local thermal equilibrium parameterization and additional absorption). The shortwave radiative transfer solver assumes plane parallel composition and is a 2-stream method. The longwave radiative transfer is an absorption-emission computation with no scattering. The radiation parameterization includes optical effects of water vapor, methane, 
ozone, halocarbons, sulfuric acid aerosols, ammonium sulfate aerosols, dust aerosols, carbonaceous aerosols, sea salt aerosols, nitrous oxide, carbon dioxide, water and ice clouds, and molecular oxygen. Aerosols implemented in the Parallel Offline Radiative Transfer (PORT) tool are identical to those implemented in CAM4. In the longwave there are 7 bands and in the shortwave there are 19 bands. PORT also includes optical characterizations of the surface and time-dependent spectral characteristics of the solar irradiance, including solar cycle variability and sun-earth geometry. The methods can be expanded to implement any constituent for which the user can construct and include appropriate optics.

The definition of radiative forcing requires the computation of radiative transfer with fixed surface and tropospheric states. An offline radiation code is therefore an ideal tool to implement this definition, as long as we have demonstrated that no significant biases are introduced by using limited time sampling. An offline model also allows for testing of (1) different radiative transfer methods, (2) alternate optical characterization of aerosol and cloud optics, (3) sensitivity to spatial distributions of chemical species, (4) sensitivity to solar irradiance, (5) surface radiative characterizations, and (6) the role of specific distributions of constituents (from observations or other models without the effects of atmospheric and surface responses.

PORT is distributed with CESM1. PORT isolates the radiation computation in CESM1/CAM4 so that radiative fluxes and heating rates can be computed without feedbacks on surface, subsurface, and atmospheric states. PORT has been used extensively with CAM4-generated data (Lamarque et al., 2011; Meehl et al., 2012; Shindell et al., 2013; Stevenson et al., 2013). Extensions for use with updated physics (CAM5) and radiation (RRTMG, Clough et al., 2005; Iacono et al., 2008) are ongoing. From CESM1, PORT inherits the parallel processing capabilities and data ingest and export methods. It also inherits the namelist specifications and netcdf file types. Users of CAM should therefore find most aspects of running PORT familiar. This paper describes PORT's implementation of both instantaneous radiative forcing and radiative forcing including stratospheric temperature adjustment.

The paper is organized as follows. In Sect. 2, we present specific details of PORT, including the implementation of the stratospheric temperature adjustment under fixed dynamical heating assumption and application to the doubling of $\mathrm{CO}_{2}$ (from $380 \mathrm{ppbv}$ to $760 \mathrm{ppbv}$ ). Section 3 discusses the error associated with sub-sampling in time. The basic methodology for computing radiative forcings is described in Sect. 4. Section 5 discusses results from the computation of the radiative forcing due to the ozone changes from 1850 to 2000. Section 6 discusses the importance of the base state on aerosol radiative forcing. Discussion and conclusions follow.

Geosci. Model Dev., 6, 469-476, 2013
Table 1. Global annual average instantaneous radiative forcing (in $\mathrm{W} \mathrm{m}{ }^{-2}$ ) due to doubling $\mathrm{CO}_{2}$ when computed with every time sample and with every 73rd time sample. Errors due to sub-sampling are small for both longwave (LW) and shortwave (SW) at both the surface and top.

\begin{tabular}{lrr}
\hline & Every sample & Every \\
\hline LW Top & 2.53904 & 2.53916 \\
SW Top & -0.01718 & -0.01718 \\
LW Surface & 1.38071 & 1.38092 \\
SW Surface & -0.04832 & -0.04843 \\
\hline
\end{tabular}

\section{Implementation of radiative forcing, including stratospheric temperature adjustment}

As defined in the Introduction, computing an instantaneous radiative forcing requires running PORT on two different atmospheric compositions (keeping the thermodynamic specifications the same) and then differencing the net radiative fluxes as illustrated in Fig. 1. The instantaneous radiative flux is typically reported at the top of the atmosphere, top of the atmospheric model, tropopause or at the surface. For all calculations below, the reference state (cam4_base.nc) is a collection of time samples of CAM4 atmospheric states and radiative fluxes from a 16-month (1 September to 31 December of the following year) present-day simulation of CAM4 with a carbon dioxide volume mixing ratio of $380 \mathrm{ppbv}$. We first checked that the calculation using PORT led to bit-for-bit identical results to the CAM4 simulation. We then doubled the carbon dioxide (as illustrated in Fig. 1) and ran PORT. Differencing the net fluxes at the top and surface gave us the instantaneous radiative forcings listed in Table 1. Sampling issues are discussed in Sect. 3.

The calculation of radiative forcing is more complicated than the calculation of instantaneous radiative forcing. The complication arises from the inclusion of the effect of stratospheric temperature adjustment. PORT implements radiative forcing similarly to Kiehl and Boville (1988) and Fels et al. (1980). In the definition of radiative forcing in Ramaswamy et al. (2001), the stratospheric temperatures are allowed to adjust to radiative equilibrium in the forced system above the tropopause, under the assumption that the dynamical heating of the stratosphere does not change. PORT prognoses the stratospheric temperature adjustment at every time step by using an explicit Euler method as discussed below.

The total heating, $H$, above the tropopause is assumed to be the sum of radiative heating, $Q$, and dynamical heating, $D$, where $T$ is the temperature and $C$ is the atmospheric composition.

$H(T, C)=Q(T, C)+D(T, C)$

The radiative heating rate, $Q(T, C)$, is the total of the shortwave and longwave heating at atmospheric temperature, $T$, by an atmosphere with composition, $C$. Under the 


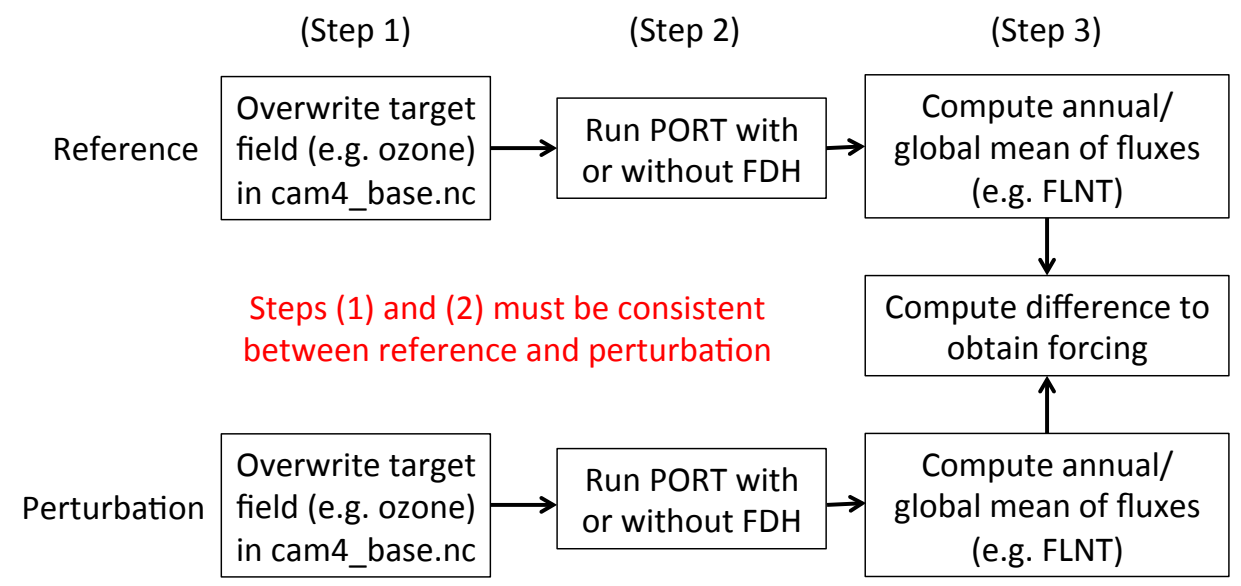

Fig. 1. Typical usage of PORT to compute radiative forcing. PORT uses the file cam4_base.nc that contains all fields needed to perform radiative computations with the CAM-RT radiative transfer scheme; these fields were generated by a present-day simulation with CESM1 and output every 73 time steps. This file therefore contains fields such temperature, humidity, clouds, albedo, aerosols, and ozone. In the reference case (top row), the file cam4_base.nc is used as such. In the perturbation case (bottom row), a specific field (for example tropospheric ozone for the year 1850) is replaced in cam4_base.nc (step 1). The two radiative calculations using PORT are therefore performed using those two separate files (step 2). The differencing of the radiation calculation results (step 3) leads to the estimate of the radiative forcing associated with the tropospheric ozone change. If users were interested in using PORT to compute ozone forcing for their model, they would replace the ozone field in the cam4_base.nc used for the reference case with their simulated 2000 ozone field, and replace the ozone field in the cam4_base.nc used for the perturbation case with their simulated 1850 ozone field. Steps 2 and 3 would then follow as indicated in Fig 1.

assumption of fixed dynamical heating, when the perturbed composition is $C_{\mathrm{p}}$ and the consequent adjusted temperature in the stratosphere is $T_{\mathrm{p}}$, the dynamical heating is assumed to be unchanged, $D(T, C)=D\left(T_{\mathrm{p}}, C_{\mathrm{p}}\right)$, but the radiative heating rates, $Q\left(T_{\mathrm{p}}, C_{\mathrm{p}}\right)$, and total heating rates, $H\left(T_{\mathrm{p}}, C_{\mathrm{p}}\right)$, in the forced system change.

$$
H\left(T_{\mathrm{p}}, C_{\mathrm{p}}\right)=Q\left(T_{\mathrm{p}}, C_{\mathrm{p}}\right)+D(T, C)
$$

The time evolution of the temperature in the unperturbed and perturbed system is given by the equations

$$
\begin{aligned}
& \frac{\mathrm{d} T}{\mathrm{~d} t}=H(T, C)=Q(T, C)+D(T, C), \\
& \frac{\mathrm{d} T_{\mathrm{p}}}{\mathrm{d} t}=H\left(T_{\mathrm{p}}, C_{\mathrm{p}}\right)=Q\left(T_{\mathrm{p}}, C_{\mathrm{p}}\right)+D(T, C) .
\end{aligned}
$$

Differencing Eqs. (3) and (4) leads to the resulting prognostic equations for stratospheric temperature adjustment, $T_{\mathrm{sa}}=T-T_{\mathrm{p}}$, in the forced system,

$$
\begin{aligned}
\frac{\mathrm{d} T_{\mathrm{sa}}}{\mathrm{d} t} & =H(T, C)-H\left(T_{\mathrm{p}}, C_{\mathrm{p}}\right) \\
& =Q(T, C)-Q\left(T_{\mathrm{p}}, C_{\mathrm{p}}\right) .
\end{aligned}
$$

The temperature adjustment is only computed above the tropopause. The tropopause is defined as the WMO lapse rate tropopause and is found using the technique of Reichler et al. (2003). This technique compensates for the coarse vertical resolution present in many GCMs. Other definitions of the troposphere can be implemented by way of the namelist.
Specifically, in our definition of stratospheric temperature adjustment, we define a mask, $M$, which is 1 for all vertical levels for which the midpoint pressure is less than the tropopause pressure and 0 elsewhere, and the diagnosis of the tropopause is based on the unadjusted temperature. The mask, $M$, can be a function of time, latitude, longitude, and altitude. In the case of doubling carbon dioxide, the stratospheric temperatures cool as can be seen in Fig. 2. As a result of the fixed dynamical heating assumption, the change in stratospheric heating (due to doubling of the carbon dioxide and the stratospheric temperature adjustment) has been driven close to zero, but the tropospheric heating rates change as can be seen in Fig. 3 .

$\frac{\mathrm{d} T_{\mathrm{sa}}}{\mathrm{d} t}=M \cdot\left(Q(T, C)-Q\left(T-M \cdot T_{\mathrm{sa}}, C_{\mathrm{p}}\right)\right)$

Equation (7) is solved using the Euler time step method. The adjustment to the stratospheric temperature in the tropics $\left(-20^{\circ}\right.$ to $\left.20^{\circ}\right)$ equilibrates over a period of about $2-3$ months as can be seen in Fig. 2. Running the model for 4 months prior to the 12-month period of the average is recommended, so that the stratospheric temperatures are in steady state before the time for a full-year (1 January-31 December) computation begins.

\section{Errors from time sub-sampling}

Typically, radiative forcing is reported as an annual global average value. Computing the radiation for every CAM4 time 


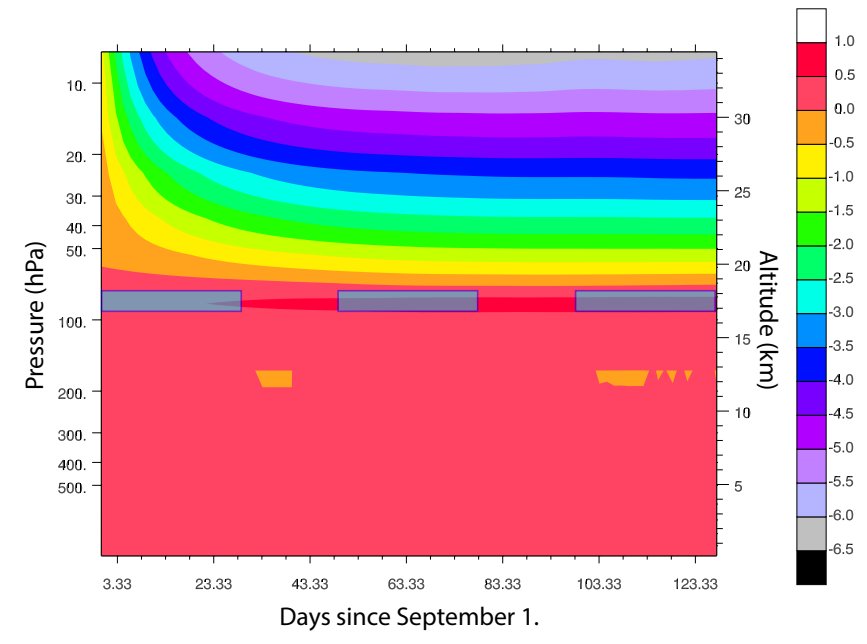

Fig. 2. Tropical $\left(-20^{\circ}\right.$ to $\left.20^{\circ}\right)$ average stratospheric temperature adjustment due to doubling $\mathrm{CO}_{2}$ as a function of time. The temperature adjustment seems to be complete 2 to 3 months after the beginning of the calculations (1 September). The average tropopause height is indicated with a dashed blue-grey line. Temperature corrections sometimes appear beneath the average tropopause height due to detection of tropopause heights lower than the average tropopause height.

step (30 min) with an offline model requires the specification of the atmosphere, surface, solar spectrum, and earth-sun geometry at that frequency, leading to a data storage of nearly $1.3 \mathrm{~TB}$.

After numerous tests, we have settled on sub-sampling the CAM4 model every 73 time steps (1.5 days plus 1 time step). This choice balances a number of different concerns: in particular, having a reasonable file size (18 GB), evenly sampling all seasons, evenly dividing the number of model time steps in a year, and most importantly sampling numerous solar angles of the direct beam at the surface.

This choice leads to a sub-sampling relative error in net fluxes of less than $0.1 \%$, as seen in Table 1 . The subsampling error in the net longwave flux correction due to the stratospheric temperature adjustment is also less than $0.01 \%$ as seen in Fig. 4. Analysis of aerosol forcing (see Sect. 6) indicates the low biases associated with our chosen 73-step sampling.

Less frequent output leads to increasing deterioration of the PORT results against high-frequency output. However, as coupling between systems (such as cloud-aerosol interactions) leads to higher correlation between forcing agents and model state (water vapor or clouds) the errors associated with sub-sampling will need to be re-evaluated.

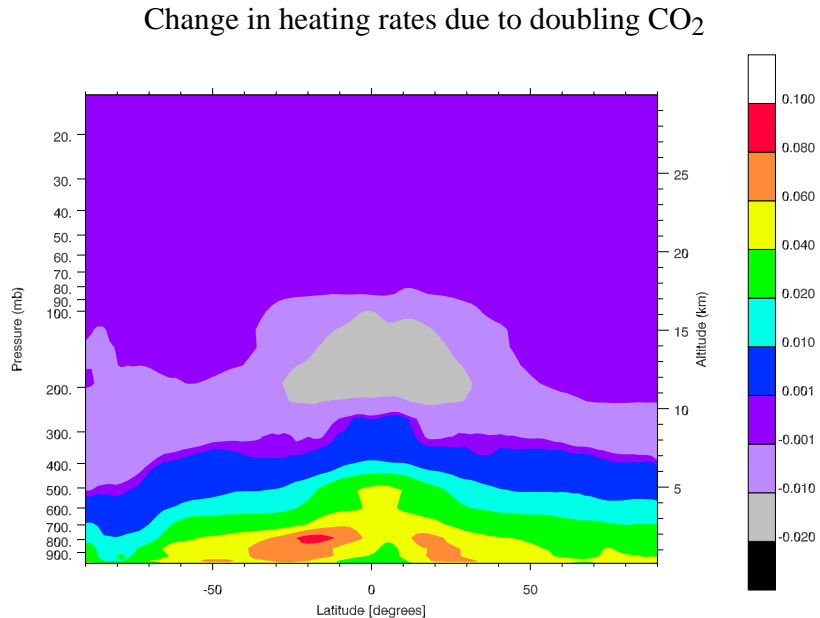

Fig. 3. Change in total (shortwave plus longwave) instantaneous annual average zonal radiative heating rate due to doubling $\mathrm{CO}_{2}$ $\left(\mathrm{Kday}^{-1}\right)$. Fixed dynamical heating was assumed in the stratosphere. Note that the predominant changes in radiative heating are in the lower troposphere.

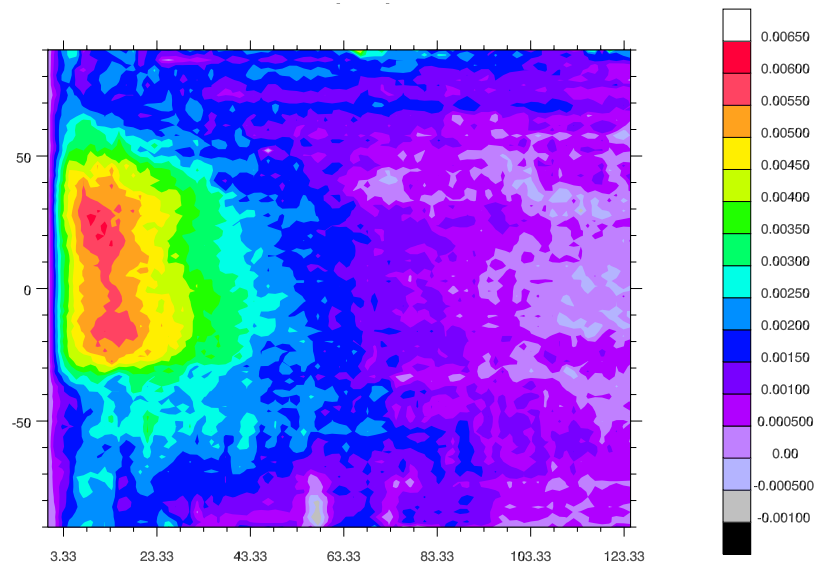

Fig. 4. Plot of the error in net longwave flux at the tropopause due to time sub-sampling as a function of latitude and days. When $\mathrm{CO}_{2}$ is doubled, the temperatures in the stratosphere relax over a period of 2 to 3 months. The difference between the net longwave flux due to sampling every time step and every 73rd time step in zonal average net flux at the tropopause is less than $0.006 \mathrm{~W} \mathrm{~m}^{-2}$ during this relaxation period.

\section{Basic usage of PORT}

A radiative forcing calculation is the difference in radiative fluxes due to a change in atmospheric composition. Figure 1 shows the steps required to perform a radiative forcing calculation using PORT. Here we describe in more details those specific steps:

1. Sample the baseline atmospheric and surface states from a run of CAM4 simulation (at least 1 September31 December of the following year is needed if FDH 
Table 2. Radiative forcing due to changes in ozone between the year 1850 and 2000 in the troposphere, stratosphere, and total (combined stratosphere and troposphere) when analyzed with PORT using fixed dynamical heating. Radiative forcing is the sum of the longwave (LW) and shortwave (SW). See Lamarque et al. (2013) for a discussion of the simulation protocol and models used.

\begin{tabular}{lcccccccc}
\hline & \multicolumn{2}{c}{ Troposphere } & & \multicolumn{2}{c}{ Stratosphere } & & \multicolumn{2}{c}{ Total } \\
\cline { 2 - 3 } \cline { 9 - 10 } RF $=$ LW + SW & SW & LW & & SW & LW & & SW & LW \\
\hline CESM-CAM-Superfast & 0.09 & 0.32 & & 0.20 & -0.23 & & 0.29 & 0.09 \\
CMAM & 0.08 & 0.23 & & 0.09 & -0.10 & & 0.16 & 0.13 \\
GEOSCCM & 0.09 & 0.28 & & 0.10 & -0.11 & & 0.19 & 0.16 \\
GFDL-AM3 & 0.10 & 0.30 & & 0.07 & -0.07 & & 0.17 & 0.23 \\
GISS-E2-R & 0.08 & 0.22 & & 0.10 & -0.23 & & 0.18 & -0.01 \\
HadGEM2 & 0.07 & 0.21 & & 0.19 & -0.24 & & 0.26 & -0.06 \\
LMDzORINCA & 0.09 & 0.26 & & -0.01 & 0.02 & & 0.08 & 0.27 \\
MIROC-CHEM & 0.09 & 0.29 & & 0.09 & -0.08 & & 0.18 & 0.20 \\
MOCAGE & 0.04 & 0.16 & & 0.46 & -0.79 & & 0.50 & -0.64 \\
NCAR-CAM3.5 & 0.10 & 0.32 & & 0.11 & -0.08 & & 0.20 & 0.24 \\
UM-CAM & 0.09 & 0.27 & & 0.14 & -0.20 & & 0.22 & 0.05 \\
\hline Multi-model & & & & & & & & \\
mean & 0.08 & 0.26 & & 0.14 & -0.19 & & 0.22 & 0.06 \\
$\sigma$ & 0.02 & 0.05 & & 0.12 & 0.21 & & 0.11 & 0.25 \\
\hline
\end{tabular}

is being used). Creating the samples requires adding three CAM namelist options specifying (1) that the data should be output, (2) in which history file to place the data, and (3) to place instantaneous samples in that file. Alternately, the user may wish to simply use the baseline state samples (cam4_base.nc) that are distributed with the code. These baseline state samples include fields from 16 months of a present-day simulation using CAM4.

2. Create two files (each based on cam4_base.nc or equivalent) to be processed by PORT. The files should only differ in the composition for which the forcing is to be computed. For example one may wish to create a file containing ozone from 1850 by overwriting the ozone levels in the baseline file with values appropriate to 1850. Similarly, create a second file containing ozone concentrations appropriate for 2100 . The file for 1850 and the file for 2100 should be identical except for the ozone concentrations, if only computing an ozone forcing.

3. Build and compile PORT using the CESM configuration tool; this simply requires adding a specific configuration flag. Run PORT twice, once for each file from the second step. Running PORT requires (1) specifying the file containing samples of the atmosphere and surface (created in the second step) and (2) specifying the case name for the output results. The user may use the namelist to output additional radiation diagnostics, such as heating rates for clear sky, or fluxes at the surface or tropopause.
4. Radiative forcing is the difference between fluxes computed in the third step as seen in Fig. (1).

Computational time and disk space can be a concern for some wanting to run PORT. PORT can be run on a typical Linux cluster. As an example, using the distribution baseline data (cam4_base.nc), sampled from an atmosphere simulation with 26 vertical levels (up to $2.3 \mathrm{hPa}$ ) and horizontal grid $\left(1.9^{\circ} \times 2.5^{\circ}\right)$ every 73 rd time step, leads to 17520 columns for each of 240 time samples from the year (about $17 \mathrm{~GB}$ ). PORT, when compiled using the Portland Group fortran compiler, processes this 16 -month data slice in $28 \mathrm{~min}$ on 8 Intel Xeon processors running at $2.67 \mathrm{GHz}$. Note that a typical PORT run will require processing 2 files of 16 months if stratospheric temperature adjustments $(\mathrm{FDH})$ are included in the radiative forcing.

\section{Application: ozone radiative forcing}

As an application, we compute here tropospheric and stratospheric ozone (separately or together) radiative forcing calculations based on the recent Atmospheric Chemistry and Climate Model Intercomparison (ACCMIP; Lamarque et al., 2013) model simulations for 1850 and 2000.

From those simulations, we extract from each model the monthly ozone distribution averaged over the period of simulation (which ranges between 1 and $10 \mathrm{yr}$ ). These files are then interpolated to the vertical (26 levels up to $2.3 \mathrm{hPa}$ ) and horizontal grid $\left(1.9 \times 2.5^{\circ}\right)$ used in the distributed base state file, cam4_base.nc. Using those interpolated monthly fields, we overwrite the tropospheric, stratospheric or total ozone 
at each corresponding month in the cam4_base.nc file, doing this separately for each model.

Note that in the present calculations, the tropopause is defined by the 150 ppbv ozone distribution in the 1850 simulation (following Young et al., 2013). Also, the monthly average field is used for all timestamps contained in the respective month (i.e. no time interpolation on the ozone field is performed). In this computation there are therefore (11 models $) \times(2$ timeslices, one for each year, 1850 and $2000) \times(3$ targets $)=66$ PORT simulations. The 3 targets are troposperic, stratospheric, and combined forcings. In all these calculations, we included the stratospheric temperature adjustment (FDH) to compute the radiative forcing.

Then, for each PORT simulation, we compute the annual/global average fluxes at the top of the model for shortwave and longwave fluxes (labeled in the netcdf output files as FLNT and FSNT, respectively). The difference for each model of the 2000 fluxes with the 1850 fluxes leads to the results listed in Table 2.

We find that, similar to results published in Ramaswamy et al. (2001), the multi-model mean tropospheric ozone RF (shortwave and longwave combined) is $0.34 \mathrm{~W} \mathrm{~m}^{-2}$ and the stratospheric ozone $\mathrm{RF}$ is $-0.05 \mathrm{~W} \mathrm{~m}^{-2}$. Interestingly, we also find that the RF from ozone over the entire column is very close to the sum of the tropospheric and stratospheric contributions, indicating the overall linearity of the perturbations discussed in this calculation.

Stevenson et al. (2013) provide an extensive comparison of tropospheric ozone radiative forcings as computed using PORT or the Edwards-Slingo radiative transfer method (Edwards et al., 1996). They found that, for the same collection of 8 different model ozone distributions, the stratospherically adjusted net (shortwave + longwave) radiative forcing is $344 \pm 66 \mathrm{~mW} \mathrm{~m}^{-2}$ for PORT and $361 \pm 68 \mathrm{~mW} \mathrm{~m}^{-2}$ for Edwards-Slingo. As both approaches lead to similar results, this confirms the usability of PORT as a tool for radiative forcing calculations, instantaneous or stratospherically adjusted.

\section{Sensitivity of aerosol radiative forcing to climate state}

Because of the importance of the hydrologic cycle in defining the distribution of aerosols, it can be expected that the aerosol and microphysical states may be correlated with clouds and water vapor. This correlation could lead to errors in estimates of the radiative forcing, especially when coupled with the time sampling strategy defined here. Since aerosols in CCSM4 are implemented as a time series of monthly average mean values (Gent et al., 2011; Meehl et al., 2012), we must test the sensitivity of aerosol radiative forcing to the underlying climate. For that purpose, we sampled CAM model states for $4 \mathrm{yr}$ and computed the present-day radiative forcing of aerosols relative to no aerosols. Looking at

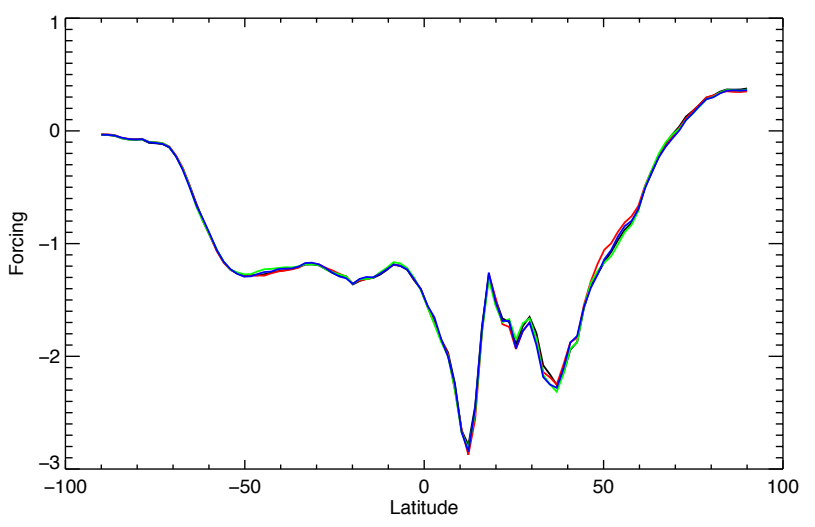

Fig. 5. Net shortwave forcing in $\mathrm{W} \mathrm{m}^{-2}$ of year 2000 aerosols at the tropopause relative to no aerosols for climate states of 4 different years. Aerosols in CAM4 are specified as monthly average values. Forcing varies between years due to variations in climate states such as water vapor, cloud cover, and land surface albedo. While these variations lead to small variation in forcing in the model, coupling of aerosols with (for example) cloud formation or wet removal could require re-examination of the errors associated with sampling of aerosol and climate states.

annual averages as shown in Fig. 5, we find that the maximum deviation at any latitude from the $4 \mathrm{yr}$ zonal average is less than $0.08 \mathrm{~W} \mathrm{~m}^{-2}$. This is in comparison to the global average forcing of $-1.3 \mathrm{~W} \mathrm{~m}^{-2}$. The global average forcing from any year is less than $0.003 \mathrm{~W} \mathrm{~m}^{-2}$ different from the $4 \mathrm{yr}$ mean. These diagnostics therefore indicate that we find little dependance of the radiative base state to the underlying climate state. As models advance to include more direct coupling between chemistry and climate (and more specifically through cloud-aerosol interactions), the sensitivity of PORT to the correlations between chemical state and climate might need to be re-evaluated.

\section{Conclusions}

In this paper, we have documented the implementation of an offline radiative transfer tool based on CESM1, PORT. In particular, PORT can take advantage of the parallelization inherent in CESM. PORT isolates the radiation code from CESM1 and provides a method for computing radiative fluxes and heating rates. With its representation of stratospheric temperature adjustment under fixed dynamical heating, PORT can be used for both radiative forcing and instantaneous radiative forcing. We have demonstrated the performance of PORT as compared to previous studies on doubling of $\mathrm{CO}_{2}$ and ozone change from the pre-industrial period (1850) to the present day (2000). We find that the ozone change agrees well with the published estimates of Ramaswamy et al. (2001) and of Stevenson et al. (2012), the latter using similar ozone distributions but different radiative 
transfer schemes than the radiation transfer scheme discussed here.

In order to limit the size of the files containing the necessary fields to perform radiative calculations, sub-sampling in time is necessary. We have found that sampling the model fields with a frequency of 73 time steps (of $30 \mathrm{~min}$ ) provide the necessary precision and therefore sampling of solar zenith angles to limit errors. In addition, we have quantified the importance of base state variability on aerosol forcing. We have found that interannual variability in the base state led to small differences, regionally and globally. Overall, running PORT on a temporal sub-sample of the original model data leads to very similar global annual averages as compared to an every-time-step sampling of the model data.

The source code for PORT is included in the CESM distribution releases 1.0.1 through 1.0.4 (see http://www.cesm. ucar.edu/models/cesm1.0/). The code for the PORT driver is located in models/atm/cam/tools/rad_driver sub-directory. Input data is provided via a public subversion repository located at https://svn-ccsm-inputdata.cgd.ucar.edu. PORT may use the same input data in addition to the radiation control data that is generated by the baseline run, as described above in Sect. 4. We recommend that potential users test PORT on their computational platform by verifying that PORT run on the base state file (distributed with PORT) produces the same fluxes as in the distributed file.

Acknowledgements. Andrew Conley, Jean-Francois Lamarque, and Francis Vitt were fully or partially supported by the SciDAC project from the Department of Energy. The National Center for Atmospheric Research is operated by the University Corporation for Atmospheric Research under sponsorship of the National Science Foundation. Many thanks to Chuck Bardeen for his helpful comments which improved an earlier version of this paper.

Edited by: T. Butler

\section{References}

Briegleb, B. P.: Delta-Eddington Approximation for Solar Radiation in the NCAR Community Climate Model, J. Geophys. Res., 97, 7603-7612, 1992.

Clough, S. A., Shephard, M., Mlawer, E., Delamere, J., Iacono, M., Cady-Pereira, K., Boukabara, S., and Brown, P.: Atmospheric radiative transfer modeling: a summary of the AER codes, J. Quant. Spectrosc. Radiat. Transfer, 91, 233-244, 2005.

Collins, W. D.: A global signature of enhanced shortwave absorption by clouds, J. Geophys. Res., 103, 31669-31679, 1998.

Collins, W. D., Hackney, J. K., and Edwards, D. P.: An updated parameterization for infrared emission and absorption by water vapor in the National Center for Atmospheric Research Community Atmosphere Model, J. Geophys. Res., 107, 4664, doi:10.1029/2001JD001365, 2002.

Edwards, J. M. and Slingo, A.: Studies with a flexible new radiation code, I: Choosing a configuration for a large-scale model, Q. J. Roy. Meteorol. Soc., 122, 689-719, 1996.
Fels, S. B., Mahlman, J. D., Schwarzkopf, M. D., and Sinclair, R. W.: Stratospheric sensitivity to perturbations in ozone and carbon-dioxide-radiative and dynamical response, J. Atmos. Sci., 37, 1084-1104, 1980.

Gent, P. R., Danabasoglu, G., Donner, L. J., Holland, M. M., Hunke, E. C., Jayne, S. R., Lawrence, D. M., Neale, R. B., Rasch, P. J., Vertenstein, M., Worley, P. H., Yang, Z. L., and Zhang, M.: The Community Climate System Model version 4, J. Climate, 24, 4973-4991, doi:10.1175/2011JCLI4083.1, 2011.

Iacono, M. J., Delamere, J., Mlawer, E., Shephard, M., Clough, S., and Collins, W.: Radiative forcing by long-lived greenhouse gases: Calculations with the AER radiative transfer models, J. Geophys. Res., 113, D13103, doi:10.1029/2008JD009944, 2008.

Kiehl, J. T. and Boville, B. A.: The Radiative-Dynamical Response of a Stratospheric-Tropospheric General Circulation Model to Changes in Ozone, J. Atmos. Sci., 45, 1798-1817, 1988.

Lamarque, J.-F., Kyle, G. P., Meinshausen, M., Riahi, K., Smith, S. J., van Vuuren, D. P., Conley, A., and Vitt, F.: Global and regional evolution of short-lived radiatively-active gases and aerosols in the Representative Concentration Pathways, Climatic Change, 109, 191-212, doi:10.1007/s10584-011-0155-0, 2011.

Lamarque, J.-F., Shindell, D. T., Josse, B., Young, P. J., Cionni, I., Eyring, V., Bergmann, D., Cameron-Smith, P., Collins, W. J., Doherty, R., Dalsoren, S., Faluvegi, G., Folberth, G., Ghan, S. J., Horowitz, L. W., Lee, Y. H., MacKenzie, I. A., Nagashima, T., Naik, V., Plummer, D., Righi, M., Rumbold, S. T., Schulz, M., Skeie, R. B., Stevenson, D. S., Strode, S., Sudo, K., Szopa, S., Voulgarakis, A., and Zeng, G.: The Atmospheric Chemistry and Climate Model Intercomparison Project (ACCMIP): overview and description of models, simulations and climate diagnostics, Geosci. Model Dev., 6, 179-206, doi:10.5194/gmd-6-179-2013, 2013.

Meehl, G., Washington, W., Arblaster, J., Hu, A., Teng, H., Tebaldi, C., Sanderson, B., Lamarque, J.-F., Conley, A., Strand, W., and White, J.: Climate system response to external forcings and climate change projections in CCSM4, J. Climate, 25, 3661-3683, doi:10.1175/JCLI-D-11-00240.1, 2012.

Ramaswamy, V., Boucher, O., Haigh, J., Hauglustaine, D., Houghton, J., Ding, Y., Griggs, D., Noguer, M., van der Linden, P., Dai, X., Maskell, K., and Johnson, C.: Radiative Forcing of Climate Change, in: Climate change 2001 : The Scientific Basis: Contribution of Working Group I to the Third Asessment Report of the Intergovernmental Panel on Climate Change, Cambridge University Press, Cambridge, United Kingdom and New York, NY, USA, 2001.

Reichler, T., Dameris, M., and Sausen, R.: Determining the tropopause height from gridded data, Geophys. Res. Lett., 30, 2042, doi:10.1029/2003GL018240, 2003.

Shindell, D. T., Lamarque, J.-F., Schulz, M., Flanner, M., Jiao, C., Chin, M., Young, P. J., Lee, Y. H., Rotstayn, L., Mahowald, N., Milly, G., Faluvegi, G., Balkanski, Y., Collins, W. J., Conley, A. J., Dalsoren, S., Easter, R., Ghan, S., Horowitz, L., Liu, X., Myhre, G., Nagashima, T., Naik, V., Rumbold, S. T., Skeie, R., Sudo, K., Szopa, S., Takemura, T., Voulgarakis, A., Yoon, J.-H., and Lo, F.: Radiative forcing in the ACCMIP historical and future climate simulations, Atmos. Chem. Phys., 13, 2939-2974, doi:10.5194/acp-13-2939-2013, 2013.

Stevenson, D. S., Young, P. J., Naik, V., Lamarque, J.-F., Shindell, D. T., Voulgarakis, A., Skeie, R. B., Dalsoren, S. B., Myhre, G., 
Berntsen, T. K., Folberth, G. A., Rumbold, S. T., Collins, W. J., MacKenzie, I. A., Doherty, R. M., Zeng, G., van Noije, T. P. C., Strunk, A., Bergmann, D., Cameron-Smith, P., Plummer, D. A., Strode, S. A., Horowitz, L., Lee, Y. H., Szopa, S., Sudo, K., Nagashima, T., Josse, B., Cionni, I., Righi, M., Eyring, V., Conley, A., Bowman, K. W., Wild, O., and Archibald, A.: Tropospheric ozone changes, radiative forcing and attribution to emissions in the Atmospheric Chemistry and Climate Model Intercomparison Project (ACCMIP), Atmos. Chem. Phys., 13, 3063-3085, doi:10.5194/acp-13-3063-2013, 2013.
Young, P. J., Archibald, A. T., Bowman, K. W., Lamarque, J.-F., Naik, V., Stevenson, D. S., Tilmes, S., Voulgarakis, A., Wild, O., Bergmann, D., Cameron-Smith, P., Cionni, I., Collins, W. J., Dalsøren, S. B., Doherty, R. M., Eyring, V., Faluvegi, G., Horowitz, L. W., Josse, B., Lee, Y. H., MacKenzie, I. A., Nagashima, T., Plummer, D. A., Righi, M., Rumbold, S. T., Skeie, R. B., Shindell, D. T., Strode, S. A., Sudo, K., Szopa, S., and Zeng, G.: Pre-industrial to end 21 st century projections of tropospheric ozone from the Atmospheric Chemistry and Climate Model Intercomparison Project (ACCMIP), Atmos. Chem. Phys., 13, 2063-2090, doi:10.5194/acp-13-2063-2013, 2013. 